\title{
Veterinary workers and disseminated sclerosis
}

\author{
A. M. G. CAMPBELL \\ From the Department of Neurology, the Royal Infirmary, Bristol
}

In 1947, Campbell, Daniel, Porter, Russell, Smith, and Innes (1947) described four veterinary research workers suffering from disseminated sclerosis, in whom the history showed that they had all worked on swayback and nervous diseases of lambs between 1938 and 1942. We have waited some time before following up these cases, because we were unable to get any clues as to why these four people, who all had similar contact with a nervous disease of sheep which itself produced demyelination and was due in part, at any rate, to a copper deficiency, should at a later date have all developed disseminated sclerosis. We also wondered whether this was pure coincidence or whether it had some bearing on the aetiology of disseminated sclerosis. Furthermore, we waited until we could see whether other contacts of these sufferers developed the disease. The time has come to follow up these cases.

The first patient was a veterinary worker whose symptoms developed in 1939 and was very severely affected by 1947 when our paper was written. At that time he showed pyramidal tract disturbances, cerebellar disturbances, and some visual loss. He died in 1953 at the age of 49 years, after three years in a bed-ridden state. A necropsy was performed on this case by Professor Lumsden of Leeds, who found pathological changes consistent with disseminated sclerosis. Death was due to bronchial pneumonia, secondary to the neurological disease, and the disease in this case had lasted 15 years from the onset of the first symptoms.

The second patient was also a veterinary officer who had worked on the swayback problem with the other patients and had sensory neurological manifestations in 1938, with an attack of retrobulbar neuritis lasting for six weeks in 1939. During the ensuing years he had mild sensory symptoms but he never developed any severe neurological incapacity and died not having consulted his own doctor about any neurological symptoms between 1939 and his death in 1955. His wife wrote and told me that he had died in 1955 of haemorrhage after gastrectomy for a chronic duodenal ulcer. Unfortunately, no necropsy was performed, but he himself was convinced that he suffered from disseminated sclerosis and his wife confirms that he had mild neurological symptoms throughout this period. Clinically, it would appear that he was a mild case of disseminated sclerosis, particularly in view of his history of retrobulbar neuritis. The time from the onset of symptoms to his death was 17 years. It is noteworthy that his sister died of disseminated sclerosis at the age of 35 years and he himself died at the age of 52 years.

The third patient, who presented first in 1939, was suffering from an acute myelitic illness from which he made a good recovery, but occasionally he had mild symptoms of weakness in the legs until he reached the age of 45 , when he developed an acute retrobulbar neuritis and lost the vision in the right eye. At this time he also had some pyramida梁 disturbances and difficulty in walking and the diagnosis made at that time was clinically that of disseminated sclerosis. He began to weaken and lose the use of his legs, and in 1953 he had to give up wore as a veterinary officer altogether. He died in 1954 of 8 perforated duodenal ulcer 14 years after the onset of the first symptoms, at the age of 45 years. It i⿺辶. unfortunate that in this case also no necropsy was performed.

The fourth patient was a laboratory worker in the same team, who developed symptoms while working with the other patients. His first symptoms occurred in 1946 when he noticed increasing difficulty in walking, with some spasticity of both legs. At first he was diagnosed as hysterical, but, over the years, he has become incapacitated with spasticity and cerebellar disturbances. He has wholly lost the sight of one eye and partially that of the other eye. When I examined him in Cambridge in 1961 when the disease had lasted for 10 years or more, he showed gross cerebellar defect, gross spasticity, and bilateral optic atrophy. He had been investigated fully at the National Hospital, Queen Square, and in St. Mary's Hospital under the care of Dr. Brinton. The cerebrospinal fluid on the last occasion showed a paretic Lange curve, and a confident diagnosis of disseminated sclerosis was made.

It is clear from these four cases that we only have pathological proof in the first case, but all the other cases appear to show the clinical criteria of disseminated sclerosis and it appears inescapable that all these four people suffered from that disease. There 
now is only one survivor. Arrangements have been made when this patient dies that we should, if possible, perform a necropsy. Unfortunately, we have not yet been able to prove the relationship or otherwise with the occupation of these four people who were working on a disease of sheep in which the aetiology does not appear to be infective but rather associated with a copper deficiency. It is, however, possible that they contracted the disease, which was not in any way related to swayback but rather to an infective illness, and that their association with swayback was coincidental. In fact one of them may have infected the others, because the second case had a sister who has disseminated sclerosis. It appears to me that these four cases strengthen the possibility that disseminated sclerosis is due to some unknown virus, but this curious group still remains a puzzle.

\section{SUMMARY}

A follow-up study of four cases of disseminated sclerosis occurring in veterinary workers all associated with work on sheep from 1938 onwards is recorded. No reasonable explanation has yet been established for this curious group of cases.

\section{REFERENCES}

Campbell, A. M. G., Daniel, P., Porter, R. J., Russell, W. R., Smith. H. V., and Innes, J. R. M. (1947). Brain, 70, 50. Lumsden, C. E. (1955). Personal communication.

\section{The October 1963 Issue}

\section{THE OCTOBER 1963 ISSUE CONTAINS THE FOLLOWING PAPERS:-}

The effect of ischaemia on nerve conduction in the carpal tunnel syndrome PAMELA M. FULLERTON

The effect of stimulus intensity on motor latency in the carpal tunnel syndrome GEORGE PRESWICK

Trans-synaptic retrograde degeneration in the visual system of primates J. M. VAN BUREN

The significance of the retinal artery pressure in cerebrovascular insufficiency J. SZAPIRO and I. ŚWIETLICZKO

Anatomical studies of the collateral blood supply to the brain and the retina J. SZAPIRO and H. PAKULA

Spindl cord infarction occurring during thoracolumbar sympathectomy J. TREVOR HUGHES and ALEX G. MACINTYRE

Neuropathological and neurochemical aspects of generalized glycogen storage disease L. CROME, J. N. CUMINGS, and S. DUCKETT
Schilder's disease (sudanophilic leucodystrophy) in five male members of one family L. CROME and M. ZA

Subacute encephalitis in an adult associated with necrotising myelitis and results of animal inoculation experiments A. M. G. CAMPBELL, R. M. NORMAN, and R. J. SANDRY

Reflex vasomotor abnormalities in the hands of migrainous subjects O. APPENZELLER, K. DAVISON, and JOHN MARSHALL

Is pregnancy order a factor in epilepsy? JULIUS D. METRAKOS and KATHERINE METRAKOS

The estimation of mean potential duration in endocrine myopathy r. A. H. YATES

On missing meningiomas AHMED EL-BANHAWY, P. W. E. SHELDON and JOE PENNYBACKER

A study of visual perseveration M. KINSBOURNE and ELIZABETH $\mathrm{K}$. WARRINGTON

Book reviews

Copies are still available and may be obtained from the PUBLISHING MANAGER, BRITISH MEDICAL ASSOCIATION, TAVISTOCK SQUARE, W.C.I., price 18s. 6D. 